\title{
REJEITO DE CAULIM DE APL DE PEGMATITO DO RN/PB - UMA FONTE PROMISSORA PARA CERÂMICA BRANCA
}

\author{
Lídia D. A. de Sousa \\ lidiadely@yahoo.com.br \\ Eiji Harima \\ Professor do Departamento de Formação de Professores do CEFE-RN \\ eharima@cefetrn.br \\ José Yvan Pereira Leite \\ Professor do Departamento de Recursos Naturais do CEFET-RN \\ leite@cefetrn.br
}

\section{RESUMO}

O presente trabalho visa à caracterização tecnológica do resíduo de caulim do ponto de vista cerâmico, gerado por pequenos mineradores da região da Província Pegmatítica de Borborema do Seridó do APL (Arranjo Produtivo Local) de Base Mineral. Estas plantas operam com até $55 \%$ de recuperação levando a rejeito com ricos. O artigo apresenta resultados de análises química, mineralógica e térmica. Também foram abordados ensaios físicos-mecânicos para verificar a retração linear de queima, a absorção de água, porosidade aparente, resistência à flexão, além da análise da microestrutura dos corpos-deprova sinterizados a $1450^{\circ} \mathrm{C}$. Os corpos-de-prova do caulim adquirido a partir do rejeito apresentaram maior retração linear de queima do que o rejeito obtido pela moagem passante de 80 mesh para as temperaturas de $950^{\circ} \mathrm{C}, 1250^{\circ} \mathrm{C}$ e $1450^{\circ} \mathrm{C}$. Em relação à absorção de água e a porosidade aparente o rejeito moído apresentou melhores resultados. Os resultados da caracterização tecnológica apontam para as possíveis aplicações desses materiais nos diversos setores produtivos, substituindo parcial ou totalmente o caulim pelo rejeito na massa cerâmica para uso em cerâmica branca, e conseqüentemente abrir novas oportunidades e dar maior sustentabilidade para as empresas locais.

PALAVRAS-CHAVE: Rejeito de caulim; caracterização tecnológica; cerâmica branca. 


\section{REJEITO DE CAULIM DE APL DE PEGMATITO DO RN/PB - UMA FONTE PROMISSORA PARA CERÂMICA BRANCA}

\section{INTRODUÇÃO}

Caulim é um tipo de argila formada essencialmente de caulinita de granulometria muito fina, possui um alto grau de pureza e geralmente apresenta cor branca após a queima. Suas principais aplicações são como agentes de enchimento e de cobertura na fabricação de papel assim como na composição de massas cerâmicas. Ainda é usado, em menor escala, na fabricação de materiais refratários, plásticos, borrachas, tintas, adesivos, cimentos, inseticidas, produtos farmacêuticos, catalisadores, fertilizantes, cosméticos, além de cargas e enchimentos para diversas finalidades.

O Brasil é o terceiro maior produtor de caulim do mundo, e junto com os Estados Unidos, detêm mais de 80\% de reserva mundial de caulim de valor econômico, (Luz et al., 2000).

O caulim pode ocorrer em dois tipos de depósito: primário e secundário. O primeiro é encontrado no local de formação pela ação de intemperismo ou hidrotermal, apresentando baixa plasticidade, baixa resistência mecânica a cru. Já o sedimentário, resulta do transporte e deposição de caulins residuais ou argilas cauliníticas por meio de correntes de água e matéria orgânica (Santos, 1975).

Na região nordeste, as principais indústrias mineradoras de caulim estão instaladas na região da Província Pegmatítica de Borborema do Seridó, localizada nos municípios do Equador (RN) e Junco do Seridó (PB). Essas mineradoras perdem em torno de $50 \%$ de caulim durante o beneficiamento. Essa grande perda é causada principalmente pela ineficiência dos processos de cominuição e classificação das usinas de tratamento de minérios, para os quais são apresentadas rotas tecnológicas para maximizar a sua recuperação (Leite et al, 2007).

A deposição deste rejeito constitui uma tarefa delicada, quer por questões econômicas, quer por questões ambientais. Por não possuir valor comercial, ele precisa ser descartado da forma mais econômica possível, minimizando, porém os impactos ambientais resultantes do processo. No caso de rejeitos sólidos secos, a deposição em áreas prédeterminadas tem equacionado o problema, as chamadas "pilhas de resíduos”. Em alguns casos, os rejeitos são utilizados para preenchimento de cavas, na recuperação ambiental de áreas já lavradas (Dutra, 2005).

A indústria de beneficiamento de caulim gera grande volume de resíduo contendo caulim, mica e quartzo. Devido a grande utilidade do caulim nos diversos setores industriais, a grande produtividade nacional, o alto valor econômico e aliado principalmente a grande perda de caulim durante o beneficiamento, o presente trabalho visa a caracterização tecnológica do resíduo de caulim gerado pelas mineradoras da região da Província Pegmatítica de Borborema do Seridó. Esta caracterização tecnológica permitirá apontar as possíveis aplicações desses materiais nos diversos setores produtivos e conseqüentemente abrir novas oportunidades e dar maior sustentabilidade para as empresas locais. 


\section{MATERIAIS E MÉTODOS}

O resíduo utilizado é proveniente do beneficiamento do caulim da região da Província Pegmatítica de Borborema do Seridó localizada em Junco do Seridó (PB) e Equador (RN). O fluxograma abaixo apresenta os ensaios de caracterização realizados no rejeito do caulim. Serão adotadas as siglas CR (Caulim do Rejeito) para identificar o caulim oriundo do peneiramento via úmido menor que 325 mesh e RCM (Rejeito de Caulim Moído) para o rejeito realizado pelo processo de moagem passante da peneira 80 mesh.

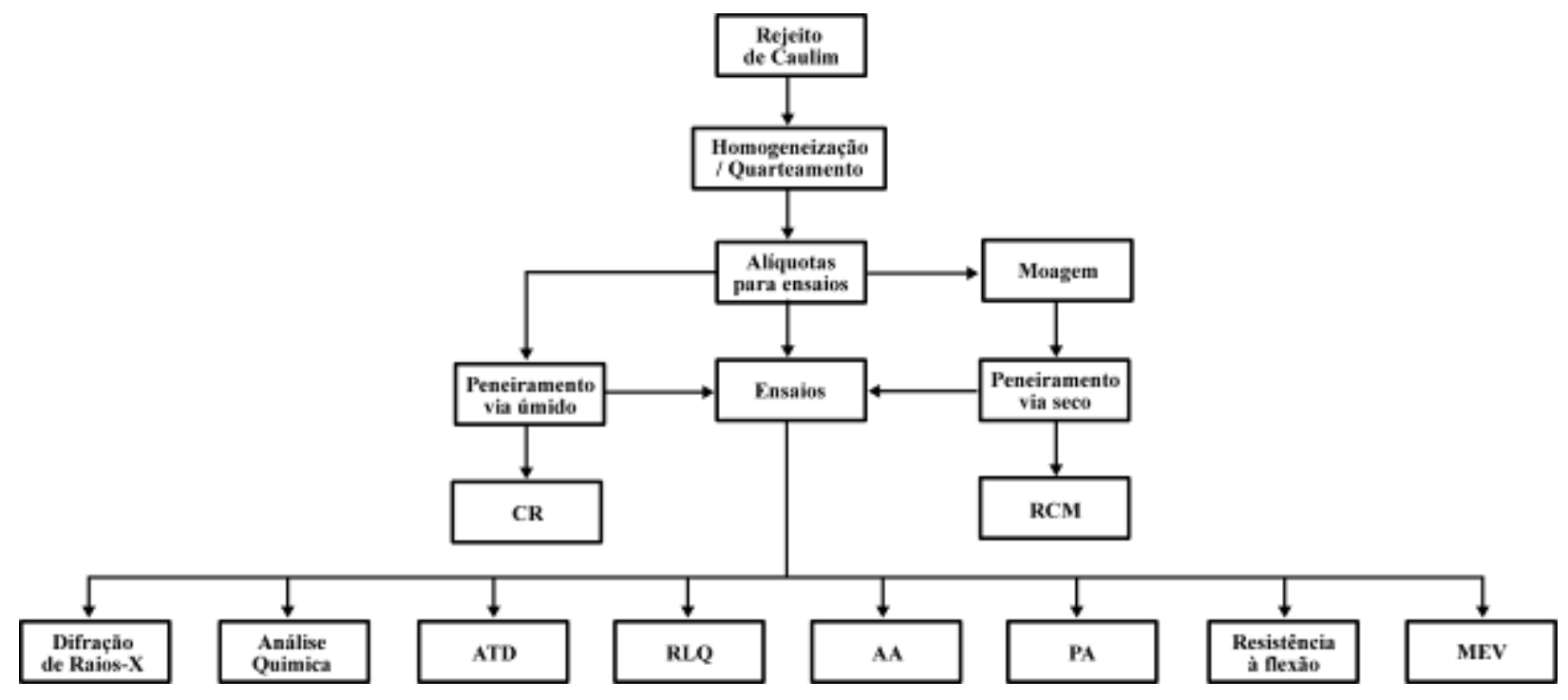

Figura 1 - Fluxograma do processo de Caracterização Tecnológica do Rejeito de Caulim

\subsection{Preparação dos corpos-de-prova}

O resíduo foi homogeneizado e quarteado, separadas alíquotas para ser realizado o peneiramento via úmido para obter o rejeito menor que $44 \mu \mathrm{m}$, o resíduo também foi moído em moinho de bolas durante 24 horas para obtenção de frações menores que 177 $\mu \mathrm{m}$. Com as amostras é possível realizar ensaios para análise comparativa dos resíduos.

Com as amostras separadas, foram ajustados os teores de umidade e em seguida granulados em peneira de $2000 \mu \mathrm{m}$. Foram confeccionados 5 corpos-de-prova (CPs), compactados em prensagem uniaxial com pressão de $200 \mathrm{kgf} / \mathrm{cm}^{2}$, com 60 × 20 x $5 \mathrm{~mm}$ de dimensões, secados a $110^{\circ} \mathrm{C}$ por 24 horas em estufa e queimados nas temperaturas de $950^{\circ} \mathrm{C}, 1250^{\circ} \mathrm{C}$ e $1450^{\circ} \mathrm{C}$ em forno Jung modelo 0713. O equipamento utilizado para compactação foi uma prensa hidráulica com capacidade para 24.000 Kgf.

\subsection{Caracterização Tecnológica}

Após resfriamento, os corpos-de-prova depois de sinterizados nas temperaturas analisadas foram medidos para determinação da Retração Linear de Queima.

De acordo com a NBR 6220, foram realizados os ensaios de Absorção, porosidade aparente e massa específica. Para a realização do ensaio de absorção de água, os corpos-de- 
prova, após sinterizados, foram imersos em água por 24 horas em um recipiente, depois desse tempo os CPs foram retirados do recipiente e removido o excesso de água superficial com um pano umedecido, com isso é possível saber a porcentagem da massa de água absorvida pelo material. Os CPs também foram colocados imersos em balança hidrostática para a medição das suas massas, com o resultado obtém-se o cálculo da porosidade aparente para saber o percentual de poros abertos presente nos corpos-de-prova em relação ao seu volume total.

O ensaio de resistência sob flexão tem como objetivo determinar a carga e a tensão máxima para corpos-de-prova padrão, utilizando-se o método de ensaio à flexão de 3 pontos. Para a realização deste ensaio foram feitos para cada amostra cinco corpos-deprova. Para obter o resultado foi feita a média em cada temperatura das duas amostras.

A análise térmica diferencial (ATD) consiste na medida da diferença de temperatura entre a substância (amostra) e o material de referência, enquanto os materiais são submetidos a uma programação controlada de temperatura. A ATD fornece informação sobre a perda de massa e as variações de energia ocorridas durante o aquecimento das amostras, que servem de indicadores das possíveis reações e transformações das fases presente no material, Moraes (2007). As curvas apresentam picos negativos (reações endotérmicas) e picos positivos (reações exotérmicas).

Foram feitas análise no MEV dos corpos-de-prova sinterizados na temperatura de $1450^{\circ} \mathrm{C}$ onde houve maior diferença no comportamento mecânico. Os CPs foram tratados com ácido fluorídrico a $2 \%$ para a remoção parcial da fase vítrea e revelar facilmente as fases cristalinas presentes nas amostras.

\section{RESULTADOS E DISCUSSÃO}

A análise mineralógica feita por Vieira (2007), figura 2 mostra que a amostra de caulim do rejeito menor que 325 mesh apresentaram dois tipos de argilominerias: caulinita e haloisita. 


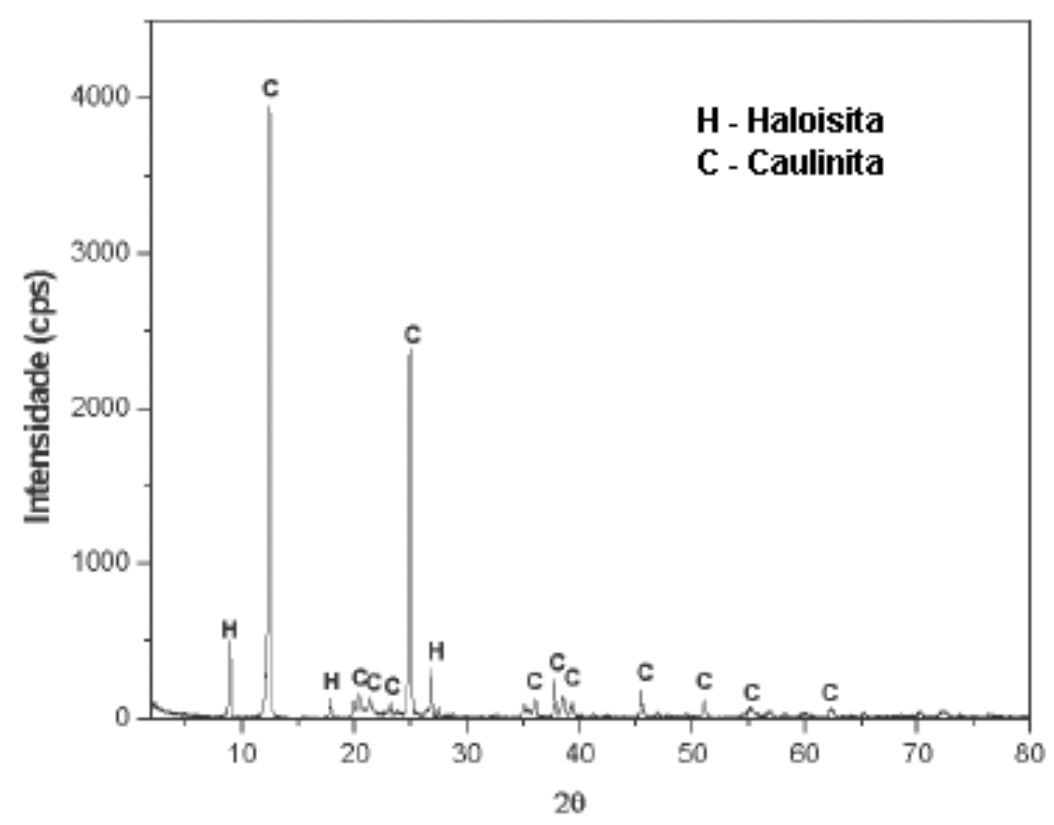

Figura 2 - Difração de Raios-X do Caulim.

A figura 3 apresenta o difratograma de raio-X obtido para o rejeito de caulim menor que 325 mesh e mostra que as fases principais sendo caulinita e muscovita e fase minoritária o quartzo.

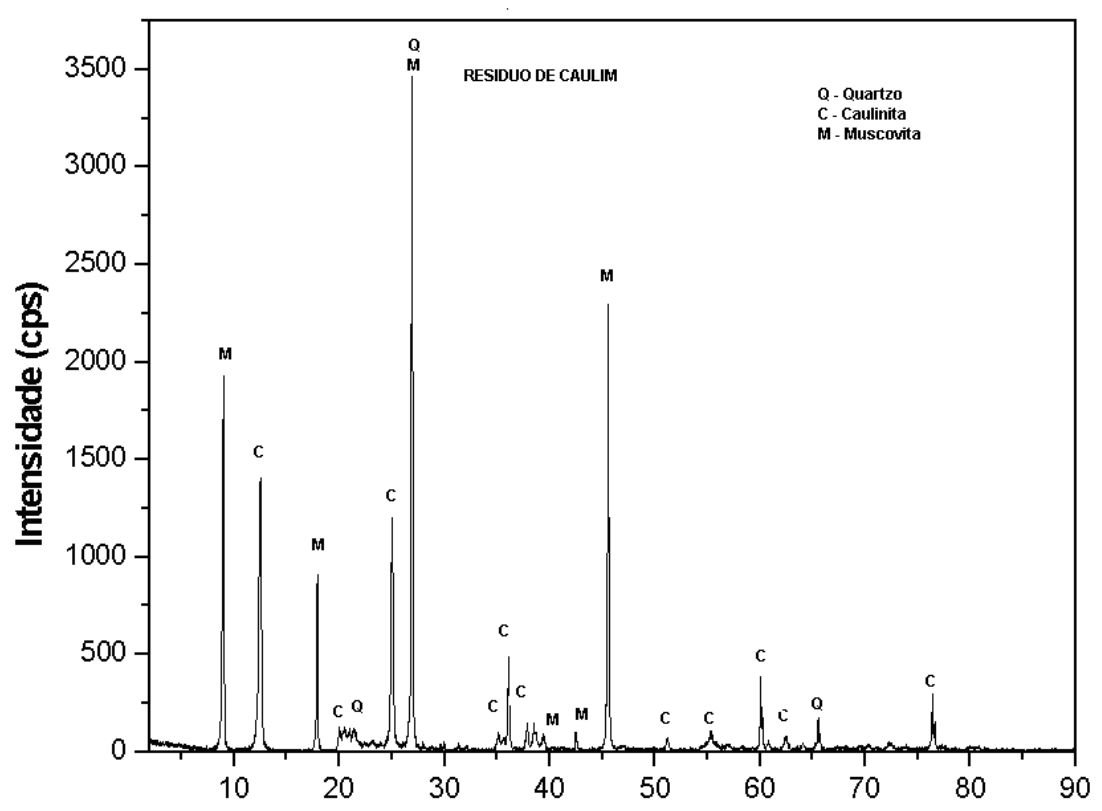

Figura 3 - Difração de Raios-X do Rejeito de caulim. Fonte: Vieira (2007).

A tabela I apresenta o resultado da análise química obtida por fluorescência de raios X no CR e RCM passante na peneira de 325 mesh. 
Tabela I - Análise química (PF = Perda ao Fogo).

\begin{tabular}{|c|c|c|c|c|c|c|c|c|c|}
\hline Óxidos & $\mathbf{S i O}_{2}$ & $\mathbf{A l}_{2} \mathbf{O}_{3}$ & $\mathbf{F e}_{2} \mathbf{O}_{3}$ & $\mathbf{T i O}_{2}$ & $\mathbf{C a O}$ & $\mathbf{M g O}$ & $\mathbf{K}_{2} \mathbf{O}$ & $\mathbf{N a}_{2} \mathbf{O}$ & Outros \\
\hline $\begin{array}{c}\text { Rejeito } \\
\text { (RCM) }\end{array}$ & $62,3 \%$ & $31,2 \%$ & $0,7 \%$ & - & - & - & $5,1 \%$ & - & $0,8 \%$ \\
\hline $\begin{array}{c}\text { Caulim } \\
\text { (CR) }\end{array}$ & $59,9 \%$ & $47,1 \%$ & $0,6 \%$ & - & - & - & $1,3 \%$ & - & $0,2 \%$ \\
\hline
\end{tabular}

Com o resultado da análise química é possível identificar as porcentagens dos óxidos presentes em cada amostras. O valor encontrado no caulim do rejeito peneirado para Al2O3 está acima do teor presente na caulinita teórica, quando é superior a $46 \%$ é classificado como sendo altamente aluminoso. O rejeito apresenta presença de $\mathrm{SiO} 2 \mathrm{em}$ maior quantidade e em pequena porcentagem do K2O encontrado devido a feldspatos, micas que são agentes fundentes e influenciam diretamente nas transformações de fases durante o aquecimento.

As figuras 3 e 4 apresentam os gráficos de análise térmica diferencial (ATD). A curva do caulim do rejeito mostra um pico endotérmico em torno de $600^{\circ} \mathrm{C}$ correspondente a desidroxilação da caulinita, transformando em metacaulinita, e um pico exotérmico em torno de $980^{\circ} \mathrm{C}$ correspondente à nucleação de mulita.

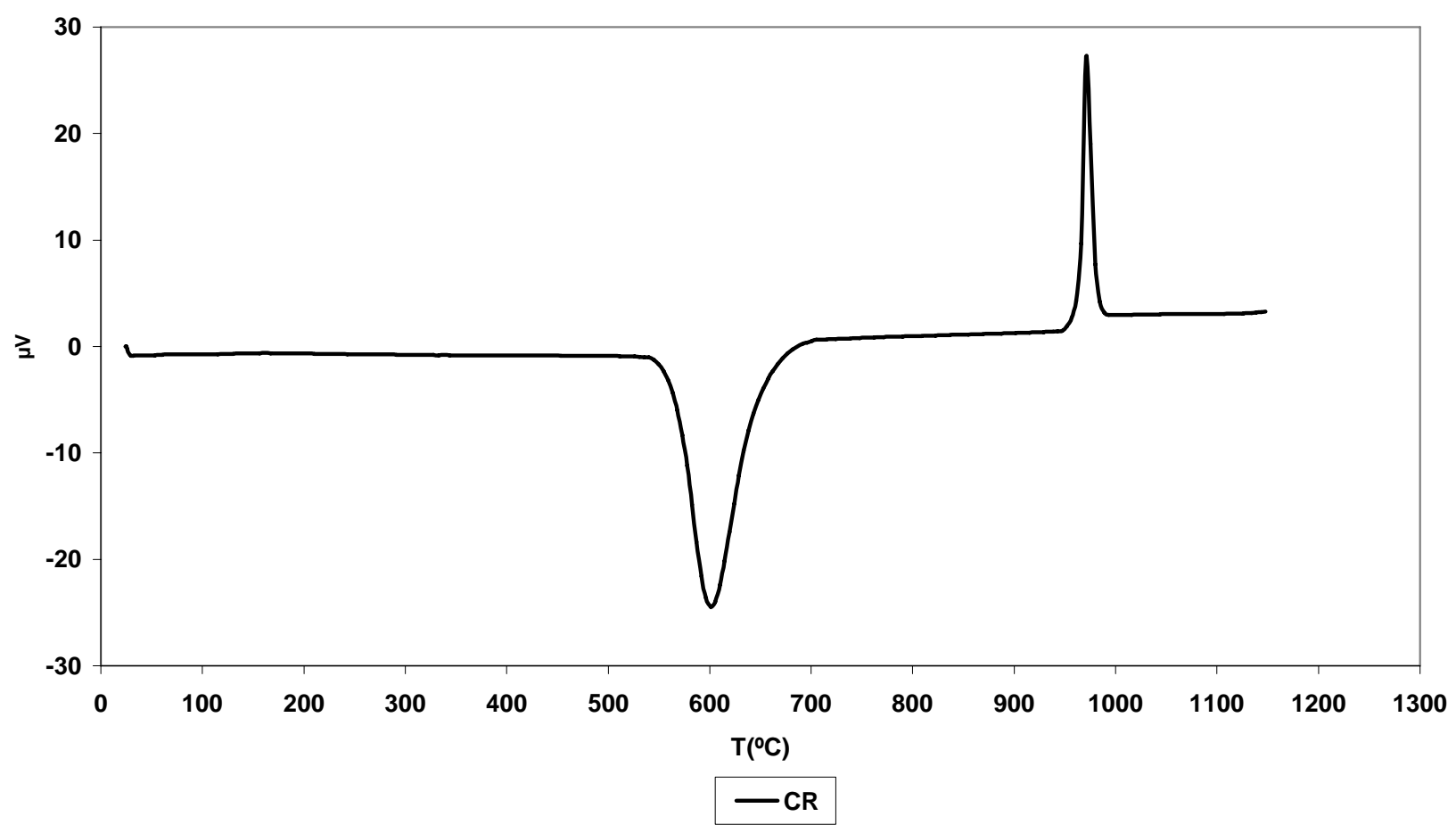

Figura 3 - Análise térmica diferencial do caulim do rejeito (CR). 


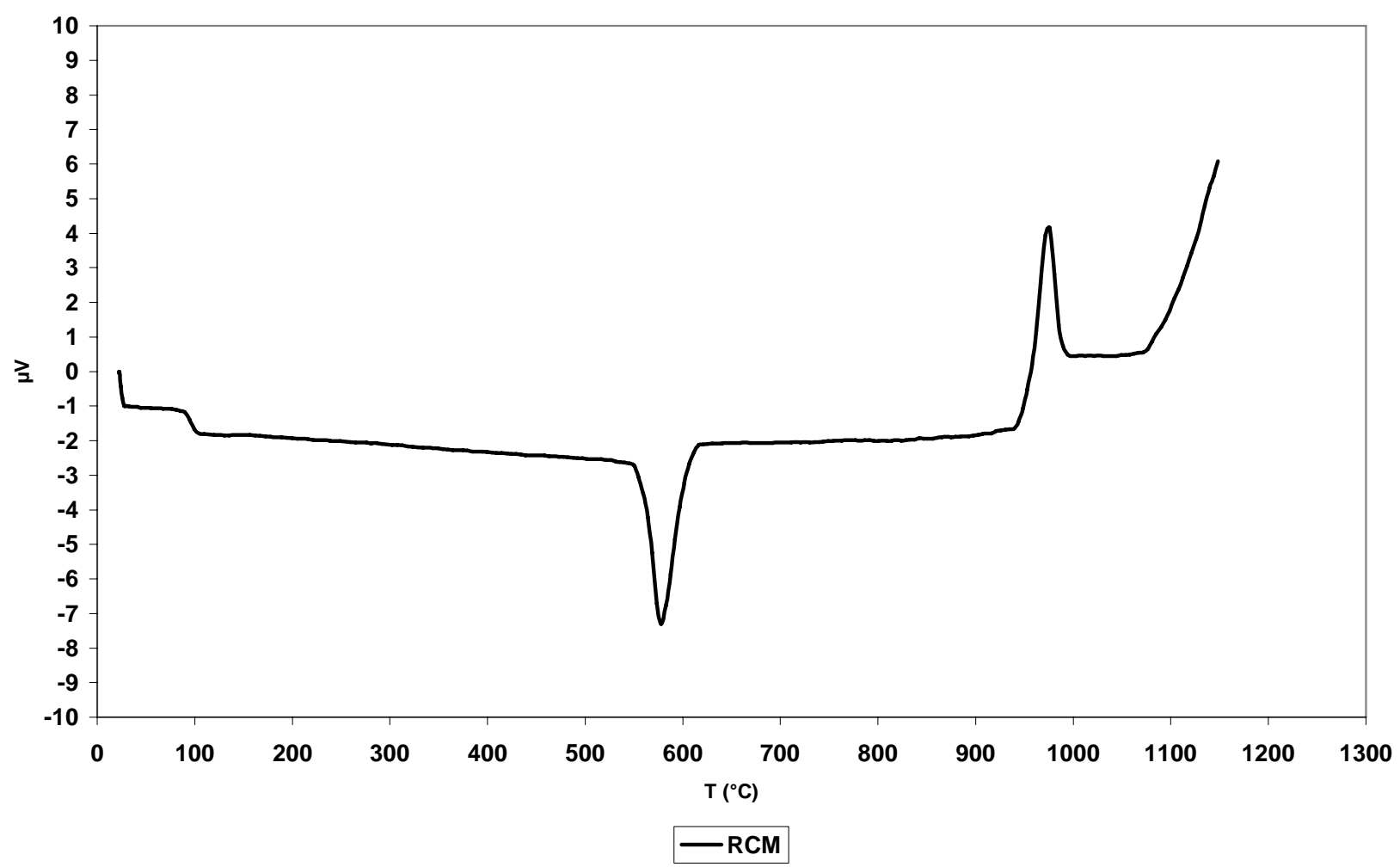

Figura 4- Análise térmica diferencial do rejeito de caulim moído (RCM).

O rejeito de caulim mostra uma queda na curva de ATD em torno de $100{ }^{\circ} \mathrm{C}$ correspondente a perda de água adsorvida. A presença de impurezas como K2O nessa amostra faz com que os picos da perda de água de constituição e da desidroxilação da caulinita se antecipem e fiquem menos acentuados. Também nessa curva pode ser observada a liberação de calor acima de $1080{ }^{\circ} \mathrm{C}$ correspondente à formação de fase vítrea devido a presença de grande quantidade de mica e de feldspato no rejeito.

A Tabela II apresenta o resultado da retração linear de queima (RLQ), absorção de água (AA), porosidade aparente (PA) e perda de massa (PA) das amostras do caulim do rejeito e do resíduo de caulim moído.

Tabela II - Retração linear de queima, absorção de água, porosidade aparente e perda de massa das amostras.

\begin{tabular}{|c|c|c|c|c|c|c|c|c|}
\hline \multirow{2}{*}{ Temperatura } & \multicolumn{2}{|c|}{ RLQ } & \multicolumn{2}{c|}{ A.A. } & \multicolumn{2}{c|}{ P.A. } & \multicolumn{2}{c|}{ P.M. } \\
\cline { 2 - 9 } & CR & RCM & CR & RCM & CR & RCM & CR & RCM \\
\hline $950^{\circ} \mathrm{C}$ & $1,45 \%$ & - & $24,62 \%$ & $20,03 \%$ & $39,53 \%$ & $32,66 \%$ & $11,42 \%$ & $3,52 \%$ \\
\hline $1250^{\circ} \mathrm{C}$ & $8,14 \%$ & $4,97 \%$ & $12,03 \%$ & $11,32 \%$ & $19,63 \%$ & $18,93 \%$ & $11,66 \%$ & $3,91 \%$ \\
\hline $1450^{\circ} \mathrm{C}$ & $14,93 \%$ & $9,01 \%$ & $0,47 \%$ & $0,56 \%$ & $0,77 \%$ & $1,01 \%$ & $11,84 \%$ & $1,49 \%$ \\
\hline
\end{tabular}


As variações nas duas amostras resultantes do ensaio de RLQ mostram que CR apresentou maior retração que o resíduo de caulim moído. Na temperatura de $950^{\circ} \mathrm{C}$ o RC apresentou uma RLQ de $1,45 \%$, enquanto que no RCM não apresentou retração na peça. No resultado de análise química verifica-se a presença de $\mathrm{SiO}_{2}$ em grande porcentagem devido a silicatos oriundos dos argilominerais, micas e os feldspatos, e sílica livre proveniente do quartzo, este causa redução, não só da plasticidade, como também leva a uma baixa retração linear, Santos (1989). Em $1250^{\circ} \mathrm{C}$ o resultado de contração linear de CR e RCM apresentam aumento proveniente do final da formação de mulita, que gera perda de massa equivalente a $11,66 \%$ para o CR e 3,91\% para o RCM. Porém para o RCM teve um pequeno acréscimo de massa na temperatura superior a $1250^{\circ} \mathrm{C}$ causado pela incorporação de oxigênio na formação vítrea.

No resultado de absorção de água (AA), nota-se o aumento na temperatura de $950^{\circ} \mathrm{C}$ e à medida que aumenta a temperatura diminuiu a absorção de água, se aproximando de zero que ocorre devido a transformações de fases vítreas e resulta no fechamento dos poros, isso se deve a grande vitrificação da superfície externa dos corpos-de-prova promovida pela presença de material fundente. O RCM possui melhor resultado que o RC até a temperatura de $1450^{\circ} \mathrm{C}$, a absorção de água aumentou para a amostra de resíduo de caulim moído, enquanto que o RC diminuiu, mas a diferença entre eles é mínima.

Observa-se na tabela II que nas duas amostras houve diminuição da porosidade com aumento da temperatura, provocando uma redução na viscosidade das fases líquidas, o que facilita o preenchimento dos espaços vazios entre as partículas que ainda não se fundiram. $\mathrm{Na}$ temperatura de $1450^{\circ} \mathrm{C}$ irá ocorrer maior quantidade de fases líquidas o que proporciona baixa porosidade nas amostras.

O gráfico abaixo representado na figura 5 apresenta os resultados de resistência mecânica à flexão de três pontos dos corpos-de-prova em função das temperaturas.

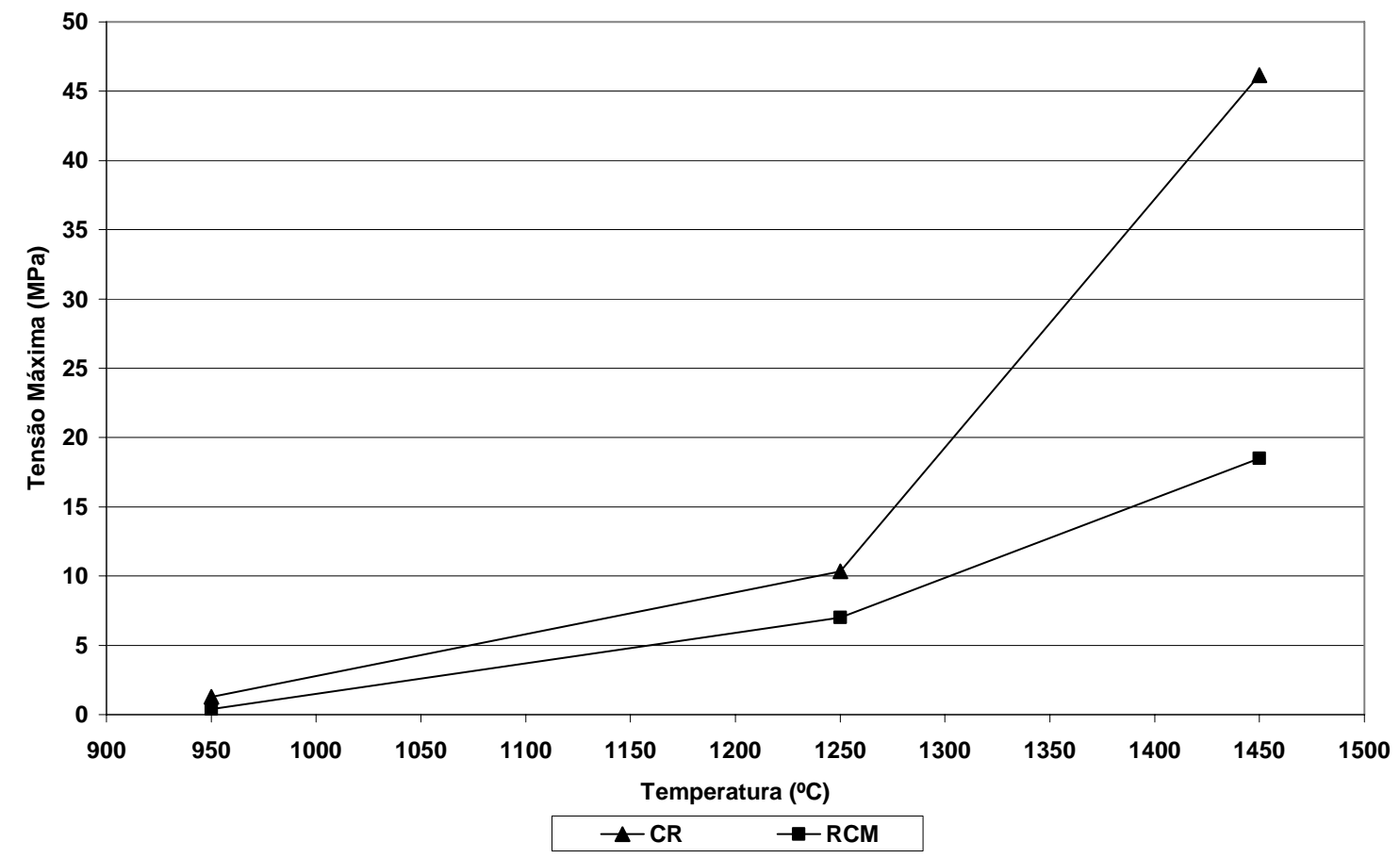

Figura 5 - Comportamento da resistência à flexão dos corpos de provas. 
Nota-se que o CR apresenta melhor resultado que RCM. Outro ponto a se destacar é a diferença considerável da resistência entre as amostras na temperatura de $1450^{\circ} \mathrm{C}$. Na amostra de CR, devido ao maior grau de sinterabilidade nessa temperatura, por apresentar partículas menores, obteve melhor resultado de resistência à flexão. Por outro lado, o RCM que possui maior quantidade de fundentes gerou aumento na formação de vidro, acarretando a diminuição da resistência mecânica.

O CR apresentou na ordem de 1,29 $\mathrm{MPa}$, 10,34 MPa e 46,16 MPa nas temperaturas de $950^{\circ} \mathrm{C}, 1250^{\circ} \mathrm{C}$ e $1450^{\circ} \mathrm{C}$, respectivamente. Enquanto que o RCM apresentou 0,41 MPa, 7 MPa e 18,5 MPa nas temperaturas analisadas. Para verificar a grande diferença na resistência à flexão apresentada pelas amostras sinterizadas a $1450^{\circ} \mathrm{C}$, foi realizada a análise no MEV.

Na figura 6 mostra a presença de mulita primária remanescente (pequenos grãos e o ponto A). A mulita secundária, de forma acicular ponto (B), aparece dissolvida na matriz vítrea (ponto C). Pode-se verificar que a mulita primária (ponto A) está sendo dispersada para formar a mulita secundária.

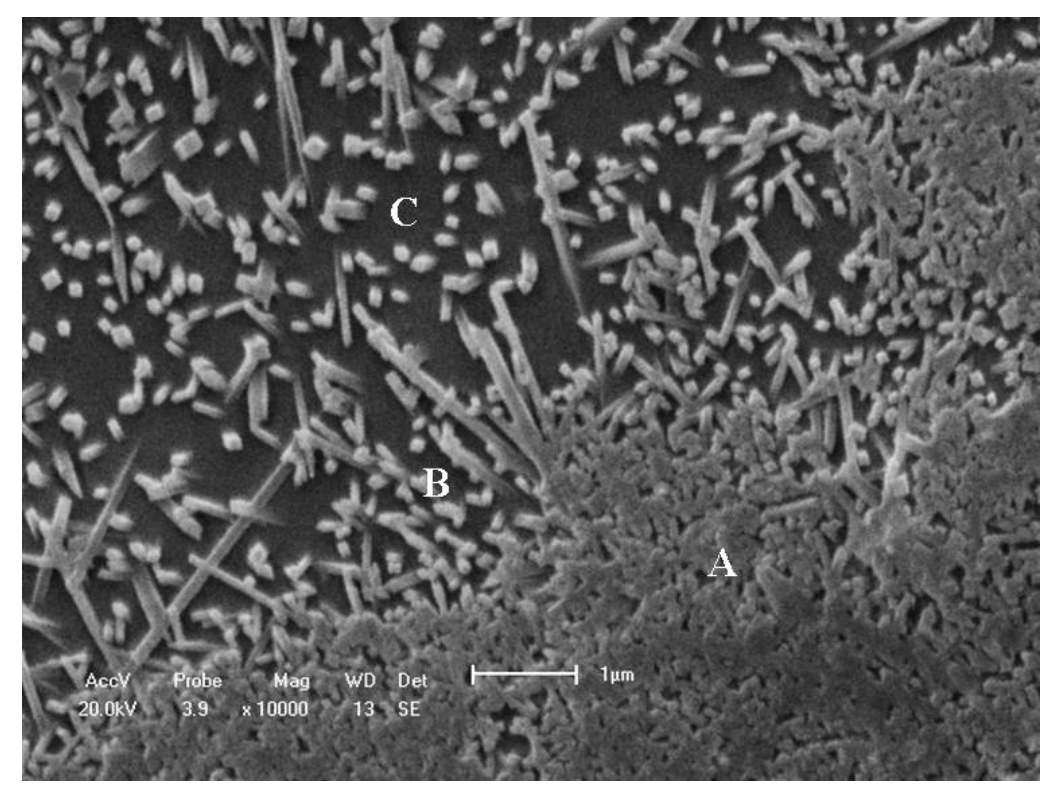

Figura 6 - Micrografia por MEV do CR sinterizado a $1450^{\circ} \mathrm{C}$ por $1 \mathrm{~h}, 10000 x$. 


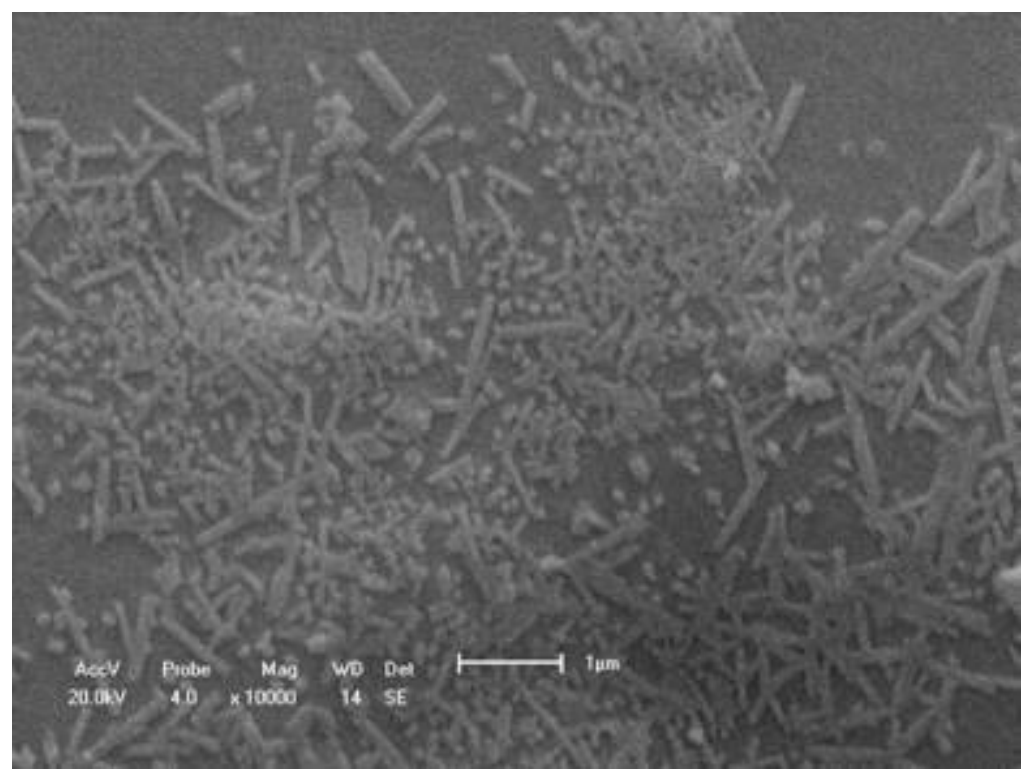

Figura 7 - Micrografia por MEV do RCM sinterizado a $1450^{\circ} \mathrm{C}$ por $1 \mathrm{~h}, 10000 x$.

Na figura 7 observa-se apenas a presença de mulita secundária. Comparando-se as duas micrografias, pode-se confirmar que a presença de fundentes (amostra RCM) provoca a formação de fase vítrea em maior quantidade, o que tem levado a dissolução da mulita. Assim é comprovado que a presença de fase mulita em menor quantidade na amostra diminui o módulo de ruptura para essa temperatura.

Moraes (2007) constata que quando o rejeito é introduzido nas massas para fabricação de revestimentos cerâmicos o rejeito de caulim causa melhorias no produto final, sem a necessidade de modificar os processos realizados pelas empresas do tipo porcelanto.

\section{CONCLUSÃO}

Em linhas gerais pode-se dizer que o caulim oriundo do rejeito, sem alteração de processo de cominuição tem maior retração linear em relação ao rejeito de caulim moído (RCM). O rejeito moído apresentou maior redução na porosidade e na absorção de água. $\mathrm{O}$ decréscimo da perda de massa a partir de $1250^{\circ} \mathrm{C}$ para o $\mathrm{RCM}$ é justificada pela incorporação de oxigênio.

Também se pode afirmar que, apesar do rejeito ter grande quantidade de fundente, a presença de quantidade razoável de quartzo tem ocasionado menor retração durante a sinterização.

Em relação a resistência à flexão, a fase vítrea apresenta uma resistência menor do que as mulitas. Assim, o módulo de ruptura desses corpos de prova depende muito da quantidade dessas fases presente na amostra. O caulim do rejeito apresenta maior sinterização, causada pelo menor tamanho de partículas (menor que 325\#) obtendo melhores resultados de flexão. Em relação ao RCM, apresenta menor resistência devido a presença de fase mulita em menor quantidade nas temperaturas superiores, por que a presença de grande quantidade de fase vítrea tem provocado dissolução da mulita secundária. 
O rejeito de caulim deve ser visto como matéria-prima promissora, pois o seu aproveitamento irá acarretar a redução por parte da empresa geradora e minimiza os custos quando aplicados na indústria cerâmica, uma vez que pode vir a substituir o caulim pelo seu resíduo na composição de massa para cerâmica branca, bem como reduzir a temperatura de sinterização devido à presença de fundentes.

\section{REFERÊNCIAS BIBLIOGRÁFICAS}

Luz, A.B.; Chaves, A.P. Tecnologia do caulim: ênfase na indústria de papel. Vol. 1. Série rochas e minerais industriais - CETEM/MCT. 2000.

Santos, P. S.; Ciência e Tecnologia de Argilas. vol. 2, p. 393-398, Edição da universidade de São Paulo, 1975.

Santos, P. S.; Ciência e Tecnologia de Argilas. vol. 1, p. 215, Edição da universidade de São Paulo, 1989.

Dutra, R; Beneficiamento dos minerais industriais. $49^{\circ}$ Congresso brasileiro de cerâmica, São Pedro - SP, 2005. Disponível em: <http://www.abceram.org.br/asp/49cb> Acesso em: 07 set 2007.

Vieira, J.D.P.; Estudo do efeito da substituição de caulim por resíduo de caulim na fabricação de cerâmica de revestimento. Natal-RN, Dissertação de Mestrado. Universidade do rio Grande do Norte, 2007.

Leite, J. Y. P.; Veras; M. M.; Santos, E.P.; Lima, R.F.S.; Paulo, J.B.A.; Mineração de Caulim de Pequena Escala em APL de Base Mineral - Novo Layout para sua Otimização. In: XXII ENTMME / VII MSHMT - Ouro Preto-MG, novembro 2007.

NBR 6220: Determinação da massa específica aparente, porosidade aparente, absorção e massa aparente da parte sólida. Associação Brasileira de Normas Técnicas. 1989.

Moraes, M. L. V. N. DE.; Utilização do resíduo do caulim na produção de piso cerâmico tipo porcelanato, Natal -RN, Tese de doutorado - Universidade federal do Rio Grande do Norte, 2007. 